\title{
"Haemoxygenase-1 induction and exhaled markers of oxidative stress in lung diseases", summary of the ERS Research Seminar in Budapest, Hungary, September, 1999
}

\author{
I. Horváth, W. MacNee, F.J. Kelly, P.N.R. Dekhuijzen, M. Phillips, G. Döring, A.M.K. Choi, \\ M. Yamaya, F.H. Bach, D. Willis, L.E. Donnelly, K.F. Chung, P.J. Barnes
}

\begin{abstract}
"Haemoxygenase-1 induction and exhaled markers of oxidative stress in lung diseases", summary of the ERS Research Seminar in Budapest, Hungary, September, 1999. I. Horváth, W. MacNee, F.J. Kelly, P.N.R. Dekhuijzen, M. Phillips, G.Döring, A.M.K. Choi, M. Yamaya, F.H. Bach, D. Willis, L.E. Donnelly, K.F. Chung, P.J. Barnes. C) ERS Journals Ltd 2001.

ABSTRACT: In recent years, there has been increasing interest in noninvasive monitoring of airway inflammation and oxidative stress. Several volatile and nonvolatile substances can be measured in exhaled breath and have been suggested as potential biomarkers of these events.

Exhaled gases, including carbon monoxide (CO), alkanes (ethane, pentane), and substances measured in breath condensate, such as hydrogen peroxide $\left(\mathrm{H}_{2} \mathrm{O}_{2}\right)$ and isoprostanes were all suggested as potential markers of oxidative stress in the lung.

A European Respiratory Society (ERS) International Research Seminar entitled "Haemoxygenase-1 induction and exhaled markers of oxidative stress in lung diseases" was organized by the Airway Regulation and Provocation Group of the Clinical Allergy and Immunology Assembly in Budapest, Hungary in September, 1999 to integrate the latest knowledge on these issues and accelerate further improvement in this area. During this 2-day event several issues were raised about: the use and standardization of measurements in exhaled breath; problems of measuring expired $\mathrm{H}_{2} \mathrm{O}_{2}$ and other mediators in breath condensate; role and regulation of haemoxygenase (HO)-1 in the lung; and conditions and factors influencing exhaled $\mathrm{CO}$.

This report is a summary of the main presentations at the seminar, together with the
\end{abstract} current areas of research in this rapidly expanding field.

Eur Respir J 2001; 18: 420-430.
National Korányi Institute for Pulmonology, Dept of Pathophysiology, Budapest, Hungary.

Correspondence: I. Horváth, National Korányi Institute for Pulmonology, Dept of Pathophysiology, Budapest, PO Box 1, Piheno u. $1 \mathrm{H}-1529$, Hungary. Fax: 3613943521

Keywords: Breath condensate exhaled air

haemoxygenase

hydrogen peroxide

inflammation

oxidative stress

Received: March 272001 Accepted: March 272001
Inflammation and oxidative stress are involved in the pathogenesis of a variety of pulmonary diseases. These pathological processes are present in several inflammatory lung conditions including asthma, chronic obstructive pulmonary disease (COPD) and cystic fibrosis $(\mathrm{CF})$. The main objectives of this international research seminar were to discuss recent results on exhaled markers of oxidative stress and the role of haemoxygenase (HO)-1 induction in different lung diseases. There were four major sections concentrating on different aspects of the mechanism and role of oxidative stress in different lung diseases and its noninvasive monitoring by the use of exhaled breath samples: The first section entitled "Oxidative stress in inflammatory lung diseases" contained three topics concentrating on the mechanism of oxidative stress in the lung, the antioxidant defences on the airway surface and the link between clinical symptoms, inflammation and oxidative stress in chronic inflammatory lung diseases. The second section
(Markers of oxidative stress in exhaled breath condensate) included talks on methods and problems of exhaled $\mathrm{H}_{2} \mathrm{O}_{2}$ measurement, exhaled markers of oxidative stress in lung diseases and on the questions of oxygen radical-mediated tissue damage in $\mathrm{CF}$. In the third section (Carbon monoxide (CO) in exhaled breath and in the lung), the introductory talks dealt with the localization of $\mathrm{HO}$ enzymes in the airways, the increase of exhaled $\mathrm{CO}$ in different lung conditions, factors influencing the level of exhaled $\mathrm{CO}$ and the protective effect of $\mathrm{CO}$ against oxidative stress. Finally, in the fourth section (Haemoxygenase-1 induction in the lung) the topics concentrated on HO-1 induction from different aspects: as a vascular protective response, its role in the inflammatory response, and its regulation by nitric oxide (NO) and cytokines in the airway epithelium. All sections were closed by a discussion when several issues were raised about these topics. In this report the introductory talks of the seminar and the main areas discussed are presented. 


\section{Oxidative stress response in inflammatory lung diseases}

\section{Mechanisms of oxidative stress in the lung}

The major source of increased oxidant burden in inflammatory lung diseases is the release of reactive oxygen species and nitrogen species (ROS and RNS, respectively) from inflammatory leukocytes and also from airway epithelial cells. In addition, inhaled oxidants such as those in cigarette smoke and air pollutants also contribute to oxidative stress, and endogenous intracellular generation of ROS and RNS also occurs.

Oxidative stress is an imbalance between oxidants and antioxidants which occurs either from an increase in oxidants and/or decrease in antioxidants. A number of antioxidant systems, both enzyme systems and sacrificial antioxidants, are present in the lungs and these vary in their importance in different sites in the respiratory tract. Oxidative stress can have a number of consequences both locally and systemically such as inactivation of antiproteineases, epithelial injury, neutrophil sequestration and migration in the lungs, and signal transduction and gene expression for proinflammatory mediators. Considerable research has focused on the regulation of redox sensitive transcription factors such as nuclear factor- $\kappa \mathrm{B}(\mathrm{NF}-\kappa \mathrm{B})$ and activation protein-1 (AP-1) which have fundamental roles in the inflammatory response. Both ROS and RNS can activate $\mathrm{NF}-\kappa \mathrm{B}$ and increase the nuclear binding of NF- $\kappa \mathrm{B}$ and AP-1. Synergistic activation of $N F-\kappa B$ can be demonstrated between ROS/RNS and inflammatory mediators such as tumour necrosis factor- $\alpha$ (TNF- $\alpha)$ which itself creates oxidative stress. Oxidative stress also produces a response involving the up-regulation of AP-1, c-Jun N-terminal kinase (JNK) and p38. One aspect of this stress response is the upregulation of protective antioxidants such as $\gamma$-glutamylcysteine synthetase, and consequently, increased glutathione production. A critical factor may therefore be the balance between these pro- and anti-inflammatory effects of oxidative stress. A further effect of oxidative stress in relation to the inflammatory response is the induction of apoptosis for which oxidants are an important signal. Although there is a considerable amount of circumstantial evidence implicating oxidative stress in the pathogenesis of many inflammatory lung diseases, this hypothesis remains to be proven. One of the problems with proving this hypothesis is the lack of effective antioxidant therapy. The development of molecules with potent antioxidant properties should allow studies on proof of the concept that redressing the oxidant/antioxidant balance using effective antioxidants may be a novel treatment in inflammatory lung diseases [1-5].

Oxidative stress and antioxidant defences on the surface of the lung

Under normal circumstances, oxidative injury of the respiratory epithelium is minimized as the extracellular surface of the lung is buffered by a thin layer of respiratory tract lining fluid (RTLF), rich in antioxidant defences. Nonenzymatic antioxidants include reduced glutathione, uric acid, vitamin $\mathrm{C}$ (ascorbic acid), and vitamin E ( $\alpha$-tocopherol). Enzymatic antioxidants include superoxide dismutase, glutathione peroxidase and catalase. It is likely that the quantity and quality of this airway antioxidant network is an important determinant of the susceptibility of the underlying respiratory epithelium to resist oxidative stress.

There are marked differences in antioxidant defences between the upper and lower respiratory tract. For example, bronchoalveolar lavage (BAL) fluid obtained from the lower respiratory tract contains the proteins caeruloplasmin and transferrin, abundant amounts of the low molecular weight antioxidants reduced glutathione and vitamin $\mathrm{C}$, and low concentrations of uric acid and $\alpha$-tocopherol. In contrast, lavage of the nasal cavity contain uric acid in large quantities, with much smaller amounts of tripeptide glutathione (GSH) and vitamin C. As the lavage procedure leads to variable dilution of RTLF from different regions of the respiratory tract, it is difficult to fully quantify these differences. For this reason, the ERS working group on "Acellular Components of BAL Fluid" have recently suggested that standardized techniques are used and all data are reported per $\mathrm{mL}$ of recovered fluid.

RTLF antioxidant status can differ markedly even between normal individuals and these differences appear to be consistent with time. Even so, there is still relatively little information available regarding the normal range of antioxidant defences in RTLF. Moreover, the sources of RTLF antioxidant defences are still unclear. For example, there is a steep concentration gradient between the RTLF and plasma glutathione pools, suggesting local synthesis or secretion of glutathione into RTLF. On the other hand, ascorbic acid concentrations appear to be similar in RTLF and plasma suggesting free movement between the circulating and airspace pools of this antioxidants. Uric acid concentrations are about half the circulating level in the lower respiratory tract, but in the nasal cavity they are at least equivalent suggesting free movement of uric acid in the upper airways. These findings suggest that different mechanisms exist for regulating the RTLF pool sizes of ascorbic acid, GSH and uric acid. At this time, the status (and response) of the RTLF antioxidant defence network in different lung pathologies is unclear. For example, in two conditions which involve inflammation of the respiratory tree, namely cigarette smoking and patients with idiopathic pulmonary fibrosis, glutathione status is quite different. In cigarette smokers, RTLF glutathione concentration is elevated with respect to controls while in patients with idiopathic pulmonary fibrosis (IPF) is decreased. Recently, it has been reported that subjects with mild asthma have low RTLF vitamin C and E concentrations. The relative importance of each antioxidant in vivo, i.e. the relative contribution of each antioxidant to the total antioxidant capacity of BALF, is not presently understood. It is likely that in certain 
circumstances, many antioxidants will act cooperatively to provide protection against oxidative damage. This question, and how RTLF antioxidant status relates individual sensitivity to oxidative stress, are both important considerations for future study design [6-8].

The link between clinical symptoms, inflammation and oxidative stress in the "puzzle" of chronic inflammatory lung diseases

Many chronic inflammatory pulmonary diseases are associated with inflammation and oxidative stress. A complex interplay between the specific cause of the disease, host characteristics and the type and intensity of inflammation and oxidative stress results in the clinical picture and likelihood of progression of that specific disease. The presence of inflammation and oxidative stress has well been established in obstructive lung diseases (asthma and COPD), interstitial lung disease, cystic fibrosis and bronchiectasis, and adult respiratory distress syndrome (ARDS). Noninvasively obtained markers of inflammation and oxidative stress have been identified, and, ideally, should represent the intensity of the ongoing pathological processes within the lungs. From a clinical point of view, physicians may expect that exhaled markers reveal insight into the pathophysiology, have a role in the assessment of the severity of inflammation/oxidative stress, predict lung function deterioration, and provide individual guidance during (pharmaco)therapy.

$\mathrm{H}_{2} \mathrm{O}_{2}$ is formed by inflammatory cells in the upper and lower airways. Increased levels have been demonstrated in patients with asthma, COPD, bronchiectasis, and ARDS. In general, exhalation of $\mathrm{H}_{2} \mathrm{O}_{2}$ appears to increase during unstable disease, and is (in asthma) related to the total number of eosinophils in sputum, and (in COPD) with the total number of polymorphonucleates (PMN)s in induced sputum. Inhaled corticosteroids (ICS) reduce the production and exhalation of $\mathrm{H}_{2} \mathrm{O}_{2}$. $\mathrm{CO}$ is produced by $\mathrm{HO}$, and has been shown to be increased in smokers, in patients with CO poisoning, in asthma, and in upper respiratory tract infections. In asthma, a correlation has been noted between exhaled $\mathrm{CO}$ and eosinophil cell counts in sputum. Exhaled $\mathrm{H}_{2} \mathrm{O}_{2}$ and $\mathrm{CO}$ have provided an insight into the pathophysiology of chronic inflammatory lung diseases, are to some extent related with the severity of inflammation/oxidative stress, and are influenced by interventions. Their predictive value and their role in assessing individual patients remains to be established [9-19].

During the discussion part of this section the role of oxidative stress in the clinical picture of inflammatory lung diseases, the relationship between symptoms and oxidant-antioxidant imbalance and factors which are capable of influencing oxidative stress response were discussed.

\section{Markers of oxidative stress in exhaled breath condensate}

\section{Methods and problems of measuring hydrogen peroxide in breath condensate}

Two methods have been described to measure $\mathrm{H}_{2} \mathrm{O}_{2}$ in breath condensate: the spectrophotometric method and the fluorometric method (table 1).

Spectrophotometric method. The interaction of $\mathrm{H}_{2} \mathrm{O}_{2}$, $3,3^{\prime}, 5,5^{\prime}$-tetramethylbenzidine (TMB) and horse radish peroxide (HRP) forms 3,3',5,5'-tetramethyl$1,1^{\prime}$-diphenoquinon-4,4'-diamine which can be measured with an absorbance of $450 \mathrm{~nm}$.

Fluorometric method. The interaction of $\mathrm{H}_{2} \mathrm{O}_{2}$, p-hydroxyphenylacetic acid (pHPA) and HRP forms 2,2'-dihydroxybiphenyl-5,5' diacetate $\left(\mathrm{p}(\mathrm{HPA})_{2}\right)$ and the fluorescence of the dimer reflects the concentration of $\mathrm{H}_{2} \mathrm{O}_{2}$.

Several factors may influence the concentration of exhaled $\mathrm{H}_{2} \mathrm{O}_{2}$ : smoking status, upper respiratory tract infections, breathing pattern, contamination with saliva and body temperature [9-19].

\section{Exhaled markers of oxidative stress in lung diseases}

Traditionally, oxidative stress has been monitored by measuring increased production of reactive oxygen

Table 1. - Methods of exhaled hydrogen peroxide measurement

\begin{tabular}{|c|c|c|c|}
\hline Reference & Pretreatment & Stability/storage & Detection limit \\
\hline \multicolumn{4}{|c|}{ Spectrophotometric method: } \\
\hline [10] & No & ? & ? \\
\hline [11] & No & 0 days & ? \\
\hline [12] & No & $6 \mathrm{~h}$ & $0.1 \mu \mathrm{M}$ \\
\hline [18] & No & 2 days & $0.1 \mu \mathrm{M}$ \\
\hline [19] & No & 2 days & $0.1 \mu \mathrm{M}$ \\
\hline \multicolumn{4}{|c|}{ Fluorometric method: } \\
\hline [14] & HPA and HRP & 1 month & $?$ \\
\hline$[13]$ & HPA and HRP & $?$ & $0.1 \mu \mathrm{M}$ \\
\hline [15] & No & 14 days & $0.1 \mathrm{nM}$ \\
\hline [16] & No & 14 days & $0.1 \mathrm{nM}$ \\
\hline [17] & No & 14 days & $0.083 \mu \mathrm{M}$ \\
\hline
\end{tabular}

HPA: hydroxyphenylacetic acid; HRP: horse radish peroxide; ?: not stated. 
species or end-products of oxidation in circulating cells and plasma. Recently, several techniques have been developed to detect oxidative stress using breath samples, which would more directly sample local production in the lungs. The major advantage of breath analysis is that it can easily be repeated, can be used in children and can be applied in patients with very severe disease where more invasive measurements are inappropriate. Several studies have reported an increase in $\mathrm{H}_{2} \mathrm{O}_{2}$ in expired condensates in lung diseases. Other molecules including nitrite and nitrate, nitrosothiols, peroxynitrite, lipid mediators, 8 -isoprostane and cytokines can also be detected in breath condensate [20-21].

Isoprostanes are stable prostaglandins formed by oxidation of arachidonic acid via a nonenzymatic pathway [22] and have been advocated as a novel index of oxidative stress. The most prevalent isoprostane species in humans is 8-isoprostane (8-epiprostaglanding $\mathrm{F} 2 \alpha$ ). Concentrations of 8-isoprostane are increased in expired condensates of patients with asthma and its level correlates with disease severity and exhaled CO level [23]. Levels of 8-isoprostane are also increased in cigarette smokers, in patients with COPD and in CF [24].

The volatile gases, ethane and pentane, can also be detected in the breath and have been used to measure lipid peroxidation to reflect oxidative stress. Exhaled pentane is increased during asthma exacerbations and decreases during recovery [25]. Exhaled ethane level is increased in cigarette smokers [26] and is reduced by high doses of antioxidant vitamins $\mathrm{C}$ and $\mathrm{E}$, but not by vitamin $\mathrm{E}$ alone $[27,28]$. Exhaled ethane levels are increased in $\mathrm{CF}$ and COPD, where there is a correlation with disease severity and with other markers of oxidative stress, such as exhaled CO. Exhaled ethane is also increased in asthma, and the levels are lower in patients treated with inhaled corticosteroids [29]. Its level is also increased in interstitial lung diseases, suggesting that it may also be a marker of lung parenchymal inflammation [30]. A disadvantage of this measurement is that it is expensive and time consuming, and avoidance of contamination with environmental ethane is important. However, it is useful as way of validating other and easier measurements of oxidative stress, such as exhaled CO [20-30].

\section{New markers of oxidative stress in the breath}

The major problems in human breath testing are:

Breath volatile organic compound collection and assay. Most volatile organic compounds (VOCs) in breath are present in picomolar concentrations, and require specialized instruments for their detection. A portable breath collection apparatus (BCA) has been developed, which collects breath VOCs onto sorbent traps for subsequent analysis by gas chromatography and mass spectroscopy. This has made it possible to perform clinical studies of breath VOCs at sites remote from a research laboratory.

Compensation for volatile organic compounds present in room air and in breath. Most VOCs in breath are also present in room air. It is therefore necessary to distinguish the breath signal from an artefact of room air contamination. Samples of breath and air VOCs are collected in order to determine the alveolar gradient of each VOC (concentration in breath-concentration in air). The alveolar gradient varies with the rate of synthesis-the rate of clearance of a VOC.

Characterization of breath volatile organic compounds in normals subjects. In a study of 50 normal subjects, 3,481 different VOCs were observed (alveolar gradient positive in 1,753 , negative in 1,728). However, a central core common to subjects comprised only 27 VOCs. These were principally isoprene, alkanes, methylalkanes, and benzene derivatives.

Determination of breath markers of oxidative stress. Alkanes are products of oxidative stress produced by lipid peroxidation of polyunsaturated fatty acids by ROS. A new breath marker of oxidative stress has been identified, the breath alkane profile. This comprised the alveolar gradient of C4-C20 alkanes plotted as a function of carbon chain length. In a study of 50 normal subjects, the mean breath alkane profile was negative from $\mathrm{C} 4-\mathrm{C} 11$ and positive from $\mathrm{C} 12-\mathrm{C} 20$. The mean age of the older half of the group was significantly greater than the younger half (47.56 yrs versus $29.88 \mathrm{yrs}, \mathrm{p}<0.0001)$, and the mean alveolar gradients of four alkanes (C5-C8) were significantly more positive in the older subjects $(p<0.05)$. There were no significant differences between males and females. It was concluded that the spectrum of alkanes in normal human breath contains apparently new markers of oxidative stress. The mean rate of clearance (via cytochrome P450 enzymes) exceeded the mean rate of synthesis (by ROSmediated oxidative stress) for $\mathrm{C} 4-\mathrm{C} 11$ alkanes, while synthesis was greater than clearance for C12-C20 alkanes. The elevated alkane profile in older subjects was consistent with an age-related increase in oxidative stress.

Detection of disease with breath markers of oxidative stress. The sensitivity and specificity of the breath alkane profile as a screening test for a number of diseases, including lung cancer, breast cancer, heart transplant rejection, and ischaemic heart disease are currently being investigated [31-32].

Does oxygen radical-mediated tissue damage occur in patients with cystic fibrosis and chronic lung infection? Patients with CF often suffer from chronic bacterial lung infections [33]. The exact mechanisms for bacterial airways colonization with several opportunistic pathogens, particularly Pseudomonas aeruginosa, in $\mathrm{CF}$ are still speculative but are most probably related to $\mathrm{CF}$ specific host factors [34]. Despite a vigorous and rapid influx of functional peripheral blood polymorphonuclear leukocytes (neutrophils) into the airways lumen, and the production of high titres of specific antibodies against the infecting pathogens, bacterial eradication is not generally achieved [34]. It was hypothesized that neutrophils cannot produce oxygen radicals in $\mathrm{CF}$ 
airways. Therefore, $\mathrm{H}_{2} \mathrm{O}_{2}$ levels were determined in breath condensates of $63 \mathrm{CF}$ patients and 51 normal subjects. Furthermore, in CF sputum samples, activities and concentrations of myeloperoxidase (MPO) and catalase (CAT) were determined as well as $\mathrm{MPO} / \mathrm{H}_{2} \mathrm{O}_{2}$-mediated cytotoxicity of $\mathrm{CF}$ sputum in cell culture assays. It was found that $\mathrm{H}_{2} \mathrm{O}_{2}$ levels were similar in CF patients and normals [35]. This may be due to the presence of scavengers of $\mathrm{H}_{2} \mathrm{O}_{2}$ in $\mathrm{CF}$ sputum specimens. Alternatively, $\mathrm{H}_{2} \mathrm{O}_{2}$ may not be produced at all in $\mathrm{CF}$ airways. High concentrations and activities of human CAT and MPO were detectable in $38 \mathrm{CF}$ sputa. Further experiments revealed that $\mathrm{CF}$ sputum, in the presence of $\mathrm{H}_{2} \mathrm{O}_{2}$, did not induce cytotoxicity in vitro, even when CAT was removed from sputum. This surprising result was due the immobilization of the highly positively charged MPO to negatively charged macromolecules present abundantly in $\mathrm{CF}$ sputum. In order to investigate whether $\mathrm{H}_{2} \mathrm{O}_{2}$ may not be produced at all in $\mathrm{CF}$ airways, it was investigated whether the oxygen partial pressure $\left(\mathrm{PO}_{2}\right)$ is reduced in the $\mathrm{CF}$ sputum. The $\mathrm{PO}_{2}$ in sputum plugs in vivo in six $\mathrm{CF}$ patients and 14 sputum specimens in vitro were assessed. The high $\mathrm{PO}_{2}$ in sputum-free $\mathrm{CF}$ bronchi dropped rapidly and significantly when the oxygen probe entered the plugs, suggesting that $\mathrm{CF}$ plugs are anaerobic. Lack of oxygen may markedly reduce bacterial killing by neutrophils due to the inability to produce ROS and thus helps to explain the chronicity of the lung infection in $\mathrm{CF}$ patients and possibly chronic lung infections in other patient groups [33-35].

The handling, storage of breath condensate, reproducibility of measurements, significance of elevated levels of mediators in condensate and the relationship between disease activity and marker levels were discussed in more detail.

\section{Carbon monoxide in exhaled breath and in the lung}

Localization of haemoxygenases in the airway wall of normal and asthmatic subjects: the effect of corticosteroid therapy

$\mathrm{HO}$ is an anti-oxidant enzyme which catabolizes haem to produce $\mathrm{CO}$ and biliverdin. Induction of $\mathrm{HO}$ activity in the lung has a protective effect against oxidant-induced inflammation and bronchial hyperresponsiveness, such as that induced by exposure to ozone. The expression and distribution of HO-1 and $\mathrm{HO}-2$, two isoenzymes of $\mathrm{HO}$ was determined, in the airways of patients with asthma, and determined the effect of inhaled corticosteroid therapy. Immunostaining for both enzymes was widely distributed in the airways submucosa, particularly in airway epithelium and submucosal macrophages (CD68+) as determined by double-immunostaining. There was no difference in intensity and extent of staining in biopsies from normal $(n=10)$ and mild asthmatic $(n=10)$ subjects. Following 1 month of treatment with inhaled corticosteroids (budesonide $1,600 \mu \mathrm{g} \cdot \mathrm{day}^{-1}$ ), there was no significant change in the expression and distribution of either HO-1 or HO-2 in the airways submucosa in eight mild asthmatics, despite a significant reduction in airway eosinophils and a reduction in bronchial responsiveness to methacholine. Levels of exhaled NO were significantly reduced, but exhaled $\mathrm{CO}$ levels remained unchanged by the treatment. Treatment with a placebo inhaler $(n=8)$ had no effect on these parameters. Thus, both HO-1 and HO-2 are extensively distributed equally in normal and asthmatics, and are not modulated by inhaled corticosteroid therapy in asthmatics. HO may be an important endogenous antioxidant enzyme [36, 37].

Increased carbon monoxide in acute asthma, upper respiratory infections and allergic rhinitis

To examine the role of endogenous $\mathrm{CO}$ in airway inflammatory diseases, exhaled $\mathrm{CO}$ concentrations were measured on a CO monitor (EC50 analyser, Bedfort Technical Instruments Ltd, Sittingbourne, $\mathrm{UK})$. CO was reproducibly detectable in the exhaled air of all subjects. The exhaled $\mathrm{CO}$ concentrations were higher in asthmatic patients not receiving inhaled corticosteroids and similar in asthmatic patients receiving inhaled corticosteroids, compared with those in nonsmoking healthy control subjects. All of 12 patients with symptomatic asthma had reductions in exhaled CO concentration 4 weeks after the initiation of inhaled corticosteroid treatment. Changes in exhaled $\mathrm{CO}$ level were significantly related to those in the eosinophil cell counts in sputum. These findings suggest an elevation of exhaled $\mathrm{CO}$ in asthmatic patients, which decreases with corticosteroid therapy. Increases in the exhaled $\mathrm{CO}$ levels may, therefore, reflect inflammation in the asthmatic airways [38]. The time course of changes in exhaled $\mathrm{CO}$ concentrations after treatment of acute exacerbation of asthma was also examined. Exacerbations of asthma caused a fall in peak expiratory flow rate (PEFR) and a rise in exhaled $\mathrm{CO}$ in all patients, and treatment with oral glucocorticoids reversed these changes in both parameters. An improvement of PEFR was closely associated with a reduction of exhaled $\mathrm{CO}$ after treatment [39]. Whether upper respiratory tract infections increase the concentration of $\mathrm{CO}$ in exhaled air of normal persons was studied. At the time of symptoms, exhaled CO concentrations were elevated, and were decreased during recovery. Recovery values of exhaled $\mathrm{CO}$ were similar to those in age-matched nonsmoking control subjects [40]. To determine whether levels of $\mathrm{CO}$ are increased in patients with seasonal allergic rhinitis, measurements of exhaled CO were made in 86 patients with allergic rhinitis during and out of the cedar pollen season [38-40]. During the season, exhaled $\mathrm{CO}$ concentrations were elevated, and decreased to normal out of the season.

\section{Exhaled carbon monoxide in lung diseases}

Exhaled CO levels are increased in various inflammatory lung diseases and may be a useful marker of inflammation/oxidative stress. The source of exhaled $\mathrm{CO}$ is likely to be the HO enzyme family. Evidence for 
this is that HO-1 expression is increased in airway macrophages and bilirubin levels are elevated in induced sputum of asthmatic patients, who present elevated exhaled $\mathrm{CO}$ level. Furthermore, exhaled CO increases after inhalation of the $\mathrm{HO}$ substrate haemin in normal subjects [41].

The levels of exhaled $\mathrm{CO}$ are increased in patients with asthma who are not treated with inhaled corticosteroids $[38,41]$. The levels are usually within the normal range in patients who are treated with inhaled corticosteroids, but patients with severe asthma who may be on high doses of inhaled steroid or maintenance oral steroids have higher levels, suggesting that exhaled $\mathrm{CO}$ may reflect disease severity [42]. CO level is also increased in childhood asthma, but only in children who are symptomatic [43]. Exhaled CO is increased in some atopic adults who are asymptomatic, although to a lesser extent than exhaled NO [44]. Exhaled CO levels are increased after allergen exposure during the late response, and also during the early response within minutes of allergen challenge [45]. Patients with COPD have a neutrophil inflammation in their airways and the levels of exhaled $\mathrm{CO}$ are increased in COPD. This is due, in part, to cigarette smoking which causes a marked elevation in exhaled $\mathrm{CO}$, but the levels of exhaled $\mathrm{CO}$ are also increased in exsmokers. Cigarette smoking causes a similar increase in exhaled $\mathrm{CO}$ in normal subjects and asthmatic patients and this effect lasts several hours. The levels of exhaled $\mathrm{CO}$ are increased in patients with bronchiectasis and it is not reduced in patients treated with inhaled corticosteroids [46]. In cystic fibrosis (CF) there is an increase in the level of exhaled $\mathrm{CO}$ and this is further increased during infective exacerbations [47, 48]. While in patients with stable $\mathrm{CF}$ inhaled steroids do not appear to affect the level of $\mathrm{CO}$, oral corticosteroids are associated with lower values. The implication of these studies is that exhaled $\mathrm{CO}$ may be useful to detect deterioration in cystic fibrosis and may be a reflection of increased oxidative stress, which also causes exhaled NO to be low by the rapid reaction of different oxidants with NO [49]. Nasal and exhaled $\mathrm{NO}$ are diagnostically low in patients with primary ciliary dyskinesia (PCD) and Kartagener's syndrome. By contrast, exhaled CO is elevated in these patients and may reflect the chronic inflammation in the lower airways of these patients [50]. The levels of exhaled $\mathrm{CO}$ are elevated in normal subjects after upper respiratory tract infections [40], in a similar manner to the increase in exhaled NO. Viral infections might directly activate $\mathrm{HO}-1$ or inducible nitric oxide synthase (iNOS) via transcription factor activation, or may induce these enzymes by increasing proinflammatory cytokines. Exhaled $\mathrm{CO}$ is also elevated in patients with lower respiratory tract infections and is reduced by antibiotic treatment.

Since $\mathrm{HO}$ is so widely distributed and is activated by many stimuli, it is likely that $\mathrm{CO}$ production is increased in many systemic diseases, and this could be reflected by an increase in exhaled $\mathrm{CO}$. Little work has been done is this area, but in the future it will be necessary to determine how different conditions might affect exhaled $\mathrm{CO}$. An increase in exhaled $\mathrm{CO}$ has been found in patients with diabetes and is related to blood glucose level and may be a reflection of the increased oxidative stress in this condition and activation of $\mathrm{HO}$ by glucose [51].

In summary, exhaled $\mathrm{CO}$ measurements are easy to make and are reproducible. CO levels are increased in several diseases of the airways, which are associated with inflammation and oxidative stress. The levels are more closely related to disease severity and symptoms than exhaled $\mathrm{NO}$, and are of potential value in diseases such as COPD, $\mathrm{CF}$ and primary ciliary dyskinesia (PCD) where exhaled NO levels are of little value. The $\mathrm{CO}$ analysers are relatively simple and cheap so this measurement may be widely available. The measurement of exhaled $\mathrm{CO}$ is not complicated by nasal contamination, which is a major issue with exhaled NO measurements. On the other hand, exhaled $\mathrm{CO}$ levels are markedly affected by environmental $\mathrm{CO}$, which may fluctuate considerably during the course of the day, particularly in cities. Previous exposure to high environmental $\mathrm{CO}$ levels may also result in subsequent increases in exhaled $\mathrm{CO}$, as $\mathrm{CO}$ dissociated from carboxyhaemoglobin. Active and passive smoking markedly affects exhaled $\mathrm{CO}$ levels and it may be important to check smoking status by measuring urinary cotinine or Nikcheck reagent strips (DynaGen Inc., Cambridge, Ma, USA). Less is known about the origin of exhaled CO than of NO. While it is likely that some exhaled $\mathrm{CO}$ is derived from airways, a large proportion of exhaled $\mathrm{CO}$ may be derived from the alveoli and may diffuse from the circulation [38-51].

\section{Factors influencing exhaled carbon monoxide level}

Exhaled $\mathrm{CO}$ is produced endogenously in healthy nonsmokers and increases in different inflammatory lung conditions. It has been suggested to be useful in monitoring inflammatory lung diseases. Before using this measurement as a noninvasive marker of disease activity, however, more needs to be known about factors that may influence exhaled CO level.

Concerning the production of $\mathrm{CO}$, the effect of exercise on the concentration and total output of exhaled $\mathrm{CO}$ in healthy subjects has been studied. During symptom-limited exercise, exhaled CO concentration showed a gradual decrease. However, $\mathrm{CO}$ output was increased approximately three-fold by the end of exercise test. CO output returned to normal $10 \mathrm{~min}$ after the test [52]. This increase in the output was similar in healthy children and adults, in asthmatic patients with or without steroid treatment, and also in patients with CF. This increase may be attributed to increased production of $\mathrm{CO}$ in the lung, probably because of sudden activation of $\mathrm{HO}-2$; however, further studies should be performed to clarify the effect of changes in $\mathrm{CO}$ gradient between the airway wall and the ambient air.

From experimental studies, hypoxia is known to be a factor modulating $\mathrm{CO}$ production. In patients with pronounced arterial hypoxia as a result of nonpulmonary diseases, for example cardiac failure, increased levels of exhaled $\mathrm{CO}$ have been found, as 
compared to nonhypoxic patients with the same condition. Improvement of their clinical condition was associated with the decrease of exhaled CO. In patients on steroid treatment, there was no elevation in exhaled $\mathrm{CO}$ level, regardless of the presence of great severity of hypoxia, suggesting that the source for increased $\mathrm{CO}$ in exhaled breath is HO-1 [53]. Not only chronically pre-existing hypoxia is able to cause an increase in exhaled $\mathrm{CO}$, but acute hypoxia may also be able to. This was shown in a study investigating children with $\mathrm{CF}$ in a stable condition. Some subjects developed hypoxia during symptom-limited exercise testing, which was followed by an increase in exhaled $\mathrm{CO}$ level after the test [52].

As the increase in $\mathrm{CO}$ production is assumed to be regulated by factors leading to oxidative stress, it seemed reasonable to investigate the effect of antioxidants on exhaled $\mathrm{CO}$ in asthma. Oral supplementation with high doses of vitamins $\mathrm{C}$ and $\mathrm{E}$ for two weeks, however, did not modulate the increased $\mathrm{CO}$ concentration in a double-blind, cross-over study in 14 mild asthmatic patients. More potent antioxidants and local application of antioxidants into the airways may influence exhaled $\mathrm{CO}$ level. Finally, while atopy by itself is known to modulate the level of exhaled NO in asthmatic patients, this does not seem to be the case for exhaled CO. There is no difference in exhaled $\mathrm{CO}$ level between atopic and nonatopic patients with the same severity of the disease [53].

In summary, several factors are able to influence exhaled $\mathrm{CO}$ level and their possible effects should be taken into account before interpreting data obtained by this measurement [52-54].

\section{Protective effects of haemoxygenase-1 and carbon monoxide against oxidative stress}

$\mathrm{HO}$ catalyses the first and rate limiting step in the degradation of haem, to yield equimolar quantities of biliverdin IXa, CO and iron [55]. Three isoforms of HO exist: HO-1 is highly inducible while HO-2 and HO-3 are constitutively expressed. Although haem is the major substrate of HO-1, a variety of nonhaem agents including heavy metals, cytokines, hormones, endotoxin and heat shock are also strong inducers of HO-1 expression [56]. This diversity of HO-1 inducers has provided further support for the speculation that $\mathrm{HO}-1$, besides its role in haem degradation, may also play a vital function in maintaining cellular homeostasis. Furthermore, HO-1 is highly induced by a variety of agents causing oxidative stress, including $\mathrm{H}_{2} \mathrm{O}_{2}$, GSH depletors, UV irradiation, endotoxin and hyperoxia [56-58]. One interpretation of this finding is that HO-1 can serve as a key biological molecule in the adaptation and/or defense against oxidative stress, which has been strengthened by recent findings in HO-1-deficient mice and humans [59, 60]. It has been shown that induction of HO-1 provides protection both in vivo and in vitro in various models of oxidative stress [56-58, 61]. Furthermore, the present authors will review additional observations that suggest exogenous administration of HO-1 by gene transfer also provides protection against oxidant stress [61], and that CO may mediate this protection [62]. CO may play an important protective role in other inflammatory disease states and thus has potential therapeutic implications.

A.M.K. Choi's laboratory have examined whether exogenous administration of $\mathrm{HO}-1$ via transgene delivery can induce HO-1 expression in the rat lung and can confer protection against oxidant induced lung injury using a rat model of hyperoxia. HO-1 messenger ribonucleic acid (mRNA) and HO-1 protein increased just hours after Ad5-HO-1 administration. The control rats exhibited marked lung haemorrhage, oedema, alveolar septal thickening, influx of inflammatory cells and fibrin deposition after $56 \mathrm{~h}$ of hyperoxia, but lung architecture was preserved in rats receiving AD5-HO-1. The present authors have also observed that rats exposed to hyperoxia alone exhibit a highly significant induction in the lung apoptotic index when compared to control rats in normoxia. In contrast, rats exposed to hyperoxia after pretreatment with Ad5-HO-1 demonstrated a significant reduction in the lung apoptotic index when compared to animals exposed to hyperoxia alone. Finally, animals receiving vehicle control all died by $66 \mathrm{~h}$ of hyperoxia exposure while a significant level of tolerance against hyperoxia was observed in rats receiving Ad5-HO-1.

Rats exposed to hyperoxia alone all died within $72 \mathrm{~h}$, while rats exposed to hyperoxia in the presence of a low concentration of $\mathrm{CO}$ exhibited highly significant tolerance to hyperoxia: all these animals were alive at the $72 \mathrm{~h}$ time point. This protective effect of $\mathrm{CO}$ is concentration dependent, with effects seen in the range 50-500 ppm. Carboxyhaemoglobin levels, a standard measurement of $\mathrm{CO}$ levels in the blood, correlated with increasing concentrations of $\mathrm{CO}$ exposure and survival of animals to lethal hyperoxia. Rats exposed to low concentrations of $\mathrm{CO}$ (50-500 parts per million (ppm)) alone did not exhibit any untoward effects [62].

In rats exposed to hyperoxia in the presence of a low concentration of $\mathrm{CO}$, a marked inhibition in the amount of pleural effusion was observed, as were significantly lower levels of protein accumulation as compared to rats exposed to hyperoxia alone. Marked lung haemorrhage, oedema, alveolar septal thickening, influx of inflammatory cells, and fibrin deposition were observed in rats exposed to hyperoxia alone. In contrast, the lungs of rats exposed to hyperoxia in the presence of CO were both macroscopically and microscopically normal. Rats exposed to hyperoxia in the presence of $\mathrm{CO}$ exhibited significant reductions in neutrophil influx and in the lung apoptotic index when compared to animals exposed to hyperoxia alone.

In summary, the potent anti-inflammatory and antiapoptotic effects described in this report and recent accumulating data demonstrating the anti-inflammatory effects of HO-1, highlight the major mechanisms by which HO-1 serves to protect cells, organs and host organisms against oxidative stress. The potential role of $\mathrm{CO}$ in mediating the protective effects of $\mathrm{HO}-1$ has also been highlighted. Future studies need to address the mechanism by which $\mathrm{CO}$ mediates these protective 
effects, either independently or in conjunction with ferritin and bilirubin [9, 10], other by-products of HO-1 [55-62].

\section{Haemoxygenase-1 induction in the lung}

\section{Haemoxygenase-1 a vascular protective response}

This section attempts to summarize the protective effects of HO-1 induction and exogenous $\mathrm{CO}$ administration relating to a model of xenotransplanting mouse hearts to rats. If the rats receive treatment which inhibits complement activation (cobra venom factor (CVF)) and blocks $\mathrm{T}$-cell responses (CyA), the mouse hearts survive indefinitely in them. If the rats are not treated, the mouse hearts are rejected in 3-5 days. Examination of the long-term surviving hearts reveals that HO-1 is up-regulated in endothelial cells (EC) and smooth muscle cells (SMC) of the heart, whereas there is much less or no up-regulation in hearts that are rejected. In order to test whether the HO-1 plays a role in survival of the hearts, HO-1deficient hearts were transplanted to rats receiving the same immunosuppression given above $(\mathrm{CVF}+\mathrm{CyA})$. Despite this treatment, the HO-1-deficient hearts were rejected in 3-7 days, clearly showing that HO-1 plays a crucial role in assuring long-term survival of the transplanted hearts in this model. To test whether carbon monoxide (CO), one of the three products of HO-1 action on haem, is in part or wholly responsible for the action of HO-1 in allowing long-term survival, tin protoporphyrin (SnPP) was used to inhibit HO-1 action. Normal (wild-type) mouse hearts transplanted to rats receiving $\mathrm{CVF}+\mathrm{CyA}+\mathrm{SnPP}$ were rapidly rejected, in a similar fashion to the HO-1-deficient hearts. The rats receiving the mouse hearts were then exposed to $\mathrm{CO}$ at $400 \mathrm{ppm}$. Under these conditions, i.e. in the absence of $\mathrm{HO}-1$ action but in the presence of exogenously administered $\mathrm{CO}$, the mouse hearts survived long-term. The experiments showed that, in this model, CO can fully replace the action of HO- 1 . Production of bilirubin was measured to ensure that HO-1 action was inhibited in the presence or absence of $\mathrm{CO}$. Mouse hearts that are rejected by rats show severe evidence of inflammation, whereas those hearts that are not rejected, do not show such signs. CO fully suppressed the inflammatory response associated with rejection. It has been shown that $\mathrm{CO}$, in some situations, can substitute for the role of HO-1, and that either agent is highly anti-inflammatory [63]. These findings could lead to clinical application of HO-1 and/or CO [63].

\section{Role of haemoxygenase-1 induction in inflammatory conditions}

WiLLIS et al. [64] have analysed the activity of HO in inflammatory cells isolated from a model of carrageenin-induced acute inflammation in the rat. HO activity was significantly higher $24 \mathrm{~h}$ after induction of inflammation. This increase in activity coincided with the appearance of the highly inducible isoform of
$\mathrm{HO}$, as determined by Western Blot analysis. Pretreatment of animals with an HO-inducer, ferriprotoporphyrin, decreased inflammatory cell number by $50 \%$ and cell exudate by $73 \%$ at $24 \mathrm{~h}$, compared to controls. These results suggest that HO may represent an endogenous protective mechanism against free radicals in acute inflammation, and may be involved in the resolution of acute inflammation. HO-1 may therefore represent a novel therapeutic target for the modulation of the inflammatory response [64].

Nitric oxide and cytokine regulation of haemoxygenase-1 induction in epithelial cells

HO- 1 can be induced by a variety of cellular stresses and inflammatory mediators $[56,65,66]$. CO, a product of $\mathrm{HO}$ activity, is elevated in the exhaled breath of subjects with various airway diseases. The cellular source of $\mathrm{CO}$ is unclear, although increased levels of HO-1 protein have been detected in sputum macrophages from asthmatic patients, when compared to normal subjects [41]. This section aims to examine whether the airway epithelium could contribute to the increased exhaled CO seen in many airway diseases.

Human primary airway epithelial cells were treated with interleukin (IL)-1 $\beta$, interferon (IFN)- $\gamma$ and tumour necrosis factor (TNF)- $\alpha$ (cytomix) for up to $24 \mathrm{~h}$ and expression of HO-1, HO-2, iNOS and reduced glyceraldehyde-phosphate dehydrogenase (GAPDH) measured by reverse transcription polymerase chain reaction. After exposure to cytomix, HO-1 expression increased at $4 \mathrm{~h}$, but decreased at $12 \mathrm{~h}$, to return to basal levels by $24 \mathrm{~h}$, but HO-2 expression did not change. The expression of iNOS followed a different time course with maximum expression at $24 \mathrm{~h}$. HO-1 expression and iNOS activity (nitrite accumulation in culture media) were not inhibited by dexamethasone. The specific iNOS inhibitor, $1400 \mathrm{~W}$, inhibited cytomix-stimulated induction of HO-1, indicating that iNOS derived NO may stimulate HO-1 induction in human primary epithelial cells. The NO donor, NOC-18 (detanonoate), induced HO-1, but had no effect on HO-2 induction. HO-1 induction was not inhibited by dexamethasone. Addition of the guanylyl cyclase inhibitor, [1-H$[1,2,4]$ oxadiaole[4,3-a]quinoxalin-1-one (ODQ), and the protein kinase $\mathrm{G}$ inhibitor, KT5823, failed to inhibit NOC-18 induction of HO-1, implying that the NO induction of HO-1 in human primary epithelial cells is via a cyclic guanosine monophosphate (GMP) independent pathway. HO-1 protein was not expressed under basal conditions; however, 24-h exposure to cytomix induced HO-1 protein, which was not inhibited by dexamethasone. HO-2 protein was expressed constitutively in these cells and was upregulated in the presence of dexamethasone. Cytomix treatment induced $\mathrm{HO}$ activity 13-fold; however, NOC-18 treatment increased $\mathrm{HO}$ activity in a dosedependent manner, with maximum activity at $500 \mu \mathrm{M}$ (23-fold). This was quite different to the effect of NOC-18 on mRNA induction. This would imply that NO may activate HO directly. There are currently no 
Table 2. - Publications relating to the use of exhaled markers in different lung conditions

\begin{tabular}{lccccc}
\hline & Asthma & COPD & Bronciectasis & Cystic fibrosis & Other conditions \\
\hline Hydrogen peroxide & {$[13,14,16,18]$} & {$[12,17]$} & {$[19]$} & {$[35,69]$} & {$[9-11,15]$} \\
Nitrite/nitrate & {$[70]$} & & & {$[21,67]$} & {$[71]$} \\
Isoprostanes & {$[23]$} & {$[71]$} & & & {$[26]$} \\
Adenosine & {$[68]$} & & & {$[31,32]$} \\
Ethane/pentane & {$[25,29]$} & & {$[46]$} & {$[47,48,52]$} & {$[40,44,50,51,53]$} \\
VOCs & {$[38,39,41-43,45,54]$} & & & & \\
Carbon monoxide & & & & \\
\hline
\end{tabular}

VOCs: volatile organic compounds; COPD: chronic obstructive pulmonary disease.

specific enzyme inhibitors and, therefore, it is not possible to determine whether this increase in activity is due to the activation of $\mathrm{HO}-1$ or HO-2.

In summary, human airway epithelial cells can be induced with cytomix to express HO-1 mRNA and protein and this is not inhibited by glucocorticosteroids. NO can also induce HO-1 and again is not steroid-sensitive. Therefore, the airway epithelium may be a source of exhaled $\mathrm{CO}$ seen in airway diseases [65-66].

\section{Conclusion}

Carbon monoxide production in the body, factors and conditions influencing exhaled carbon monoxide, and, possible sources of exhaled carbon monoxide were discussed. The regulation of haemoxygenase- 1 and haemoxygenase- 2 activity, mechanisms of haemoxygenase- 1 induction by inflammatory mediators and reactive oxygen species, and the multiple effects and role of the end-products of haemoxygenase activity under physiological and pathophysiological conditions were discussed in detail. Table 2 summarizes the references on the most studied exhaled biomarkers in different lung conditions (exhaled nitric oxide is not included).

Acknowledgements. The seminar was sponsored by the European Respiratory Society with additional help from the Hungarian Respiratory Society and the Science and Technology Programme of the Hungarian Ministry of Education.

Seminar chair: P.J. Barnes. Initiator and coordinator: I. Horváth. Participants: I. Adcock, UK; I. Rahman, UK; K. Thethi, UK; L. Otterbein, USA; D. Dyck, USA; M. Soares, USA; S. Loukides, Greece; P.J. Barnes, UK; S. Petruzzelli, Italy; R. Foresti, UK; G. Döring, Germany; G. Joos, Belgium; A. Antczak, Poland; G. Becher, Germany; F. Kelly, UK; A.M.K. Choi, USA; P.N.R. Dekhuijzen, the Netherlands; W. MacNee, UK; M. Phillips, USA; F. Bach, USA; M. Yamaya, Japan; Z. Csoma, Hungary; G. Losonczy, Hungary; P. Magyar, Hungary; G. Papp, Hungary; É. Huszár, Hungary; E. Barát, Hungary; G. Böszörményi-Nagy, Hungary; R. Horváth, Hungary; I. Herjavecz, Hungary; J. Strausz, Hungary; Z. Lohinai, Hungary; L. Donnelly, UK; J. Homolka, Czech Republic; E. Hídvégi, Hungary; K.F. Chung, UK; M. Leckie, UK; N. Sterfors, Sweden; D. Willis, UK; T. Lawrence, UK; P. Paredi, UK; B. Bálint,
Hungary; C. Dunster, UK; J.T. Chapman, USA; K. Ganas, Greece; Z. Novák, Hungary; R. Motterlini, UK; D. Worlitzsch, Germany; M. Krol, Poland; K. Nakayama, Japan; S. Culpitt, UK; K. Torén, Sweden; A-C. Olin, Sweden; I. Horváth, Hungary.

\section{References}

1. MacNee W, Rahman I. Oxidants and antioxidants as therapeutic targets in chronic obstructive pulmonary disease. Am J Respir Crit Care Med 1999; 160: S58S65.

2. Rahman I, MacNee W. Role of transcription factors in inflammatory lung diseases. Thorax 1998; 53: 601612.

3. Rahman I, MacNee W. Lung glutathione and oxidative stress: implications in cigarette smokeinduced airway diseases. Am J Physiol 1999; 277: L1067-L1088.

4. Lander HM. An essential role for free radicals and derived species in signal transduction. FASEB J 1997; 11: 118-124.

5. Repine JE, Bast A, Lankhorst I and the Oxidative stress Study Group. Oxidative stress in chronic obstructive pulmonary disease. State of art. $\mathrm{Am}$ J Respir Crit Care Med 1997; 156: 341-357.

6. Kelly FJ, Mudway IS. Sensitivity to ozone: could it be related to an individuals complement of lung epithelium lining fluid antioxidants? Redox Report 1997; 3 : 199-206.

7. Kelly FJ, Mudway I, Blomberg A, Frew A, Sandstrom $\mathrm{T}$. Altered lung antioxidant status in patients with mild asthma. Lancet 1999; 354: 482-483.

8. Kelly FJ, Buhl R, Sandstrom T. Measurement of antioxidants, oxidants and oxidant products in bronchoalveolar lavage fluid. Eur Respir Rev 1999; 9: 93-98.

9. Baldwin SR, Grum CM, Boxer LA, Simon RH, Ketai LH, Devall LJ. Oxidant activity in expired breath of patients with adult respiratory distress syndrome. Lancet 1986; I: 11-14.

10. Sznajder JI, Fraiman A, Hall JB, et al. Increased hydrogen peroxide in the expired breath of patients with acute hypoxemic respiratory failure. Chest 1989; 96: 606-612.

11. Wilson WC, Laborde PR, Benumof JL, Taylor R, Swetland JF. Reperfusion injury and exhaled hydrogen peroxide. Anesth Analg 1993; 77: 963-970.

12. Dekhuijzen PN, Aben KKH, Dekker I, et al. Increased exhalation of hydrogen peroxide in patients with stable and unstable chronic obstructive 
pulmonary diseases. Am J Respir Crit Care Med 1996; 154: 813-816.

13. Jöbsis Q, Raatgeep HC, Hermans PWM, de Jongste JC. Hydrogen peroxide in exhaled air is increased in stable asthmatic children. Eur Respir J 1997; 10: 519521.

14. Dohlman AW, Black HR, Royall JA. Expired breath hydrogen peroxide is a marker of acute airway inflammation in pediatric patients with asthma. Am Rev Respir Dis 1993; 148: 955-960.

15. Nowak D, Antczak A, Krol M, et al. Increased content of hydrogen peroxide in the expired breath of cigarette smokers. Eur Respir J 1996; 9: 652-657.

16. Antczak A, Nowak D, Shariati B, Krol M, Piasecka G, Kurmanowska Z. Increased hydrogen peroxide and thiobarbituric acid-reactive products in expired breath condensate of asthmatic patients. Eur Respir $J$ 1997; 10: 1235-1241.

17. Nowak D, Kasielski M, Pietras T, Bialasiewicz P, Antczak A. Cigarette smoking does not increase hydrogen peroxide levels in expired breath condensate of patients with stable COPD. Monaldi Arch Chest Dis 1998; 53: 268-273.

18. Horvath I, Donnelly LE, Kiss A, et al. Combined use of exhaled hydrogen peroxide and nitric oxide in monitoring asthma. Am J Respir Crit Care Med 1998; 158: 1046-1048.

19. Loukides S, Horvath I, Wodehouse T, Cole PJ, Barnes PJ. Elevated levels of expired breath hydrogen peroxide in bronchiectasis. Am J Respir Crit Care Med 1998; 158: 991-994.

20. Becher G, Winsel K, Beck E, Neubauer G, Stresemann E. Breath condensate as a method of noninvasive assessment of inflammation mediators from the lower airways. Pneumologie 1997; 51: 456-459.

21. Corradi M, Montuschi P, Donnelly LE, Hodson ME, Kharitonov SA, Barnes PJ. Nitrosothiols and nitrite in exhaled breath condensate of patients with cystic fibrosis. Am J Respir Crit Care Med 1999; 159: A682.

22. Morrow JD, Roberts LJ. The isoprostanes. Current knowledge and directions for future research. Biochem Pharmacol 1996; 51: 1-9.

23. Montuschi P, Ciabattoni $\mathrm{G}$, Corradi $\mathrm{M}$, et al. Increased 8-Isoprostane, a marker of oxidative stress, in exhaled condensates of asthmatic patients. $\mathrm{Am} \mathrm{J}$ Respir Crit Care Med 1999; 160: 216-220.

24. Montuschi P, Kharitonov SA, Ciabattoni G, et al. Exhaled 8-isoprostane as a new non-invasive biomarker of oxidative stress in cystic fibrosis. Thorax 2000; 55: 205-209.

25. Olopade CO, Zakkar M, Swedler WI, Rubinstein I. Exhaled pentane levels in acute asthma. Chest 1997; 111: 862-865.

26. Habib MP, Clements NC, Garewal HS. Cigarette smoking and ethane exhalation in humans. $A m$ J Respir Crit Care Med 1995; 151: 1368-1372.

27. Do BK, Garewal HS, Clements NC Jr, Peng YM, Habib MP. Exhaled ethane and antioxidant vitamin supplements in active smokers. Chest 1996; 110: 159164.

28. Habib MP, Tank LJ, Lane LC, Garewal HS. Effect of vitamin $\mathrm{E}$ on exhaled ethane in cigarette smokers. Chest 1999; 115: 684-690.

29. Paredi P, Leak D, Ward S, Cramer D, Kharitonov SA, Barnes PJ. Increased exhaled ethane in exhaled air of asthmatic patients. Am J Respir Crit Care Med 1999; 159: A97.
30. Paredi P, Ward S, Cramer D, du Bois RM, Kharitonov SA, Barnes PJ. Exhaled ethane is increased in cryptogenic fibrosing alveolitis and fibrosing alveolitis associated with systemic sclerosis. Am J Respir Crit Care Med 1999; 159: A66.

31. Phillips M, Herrera J, Krishnan S, Zain M, Greenberg $\mathrm{J}$, Cataneo RN. Variation in volatile organic compounds in the breath of normal humans. J Chromatogr B Biomed Sci App 1999; 729: 75-88.

32. Phillips M, Gleeson K, Hughes JM, et al. Volatile organic compounds in breath as markers of lung cancer: a cross-sectional study. Lancet 1999; 353: 1930-1933.

33. Hoiby N. Microbiology of lung infections in cystic fibrosis patients. In: Hodson ME, Geddes $\mathrm{D}$, eds. Cystic Fibrosis. Chapmen and Hall, London, 1995; pp. 75-98.

34. Döring G, Knight R, Bellon G. Immunology of cystic fibrosis. In: Hodson ME, Geddes D, eds. Cystic Fibrosis. Chapmen and Hall, London, 1995; pp. 99129.

35. Worlitzsch D, Herberth $G$, Ulrich M, Döring G. Catalase, myeloperoxidase and hydrogen peroxide in cystic fibrosis. Eur Respir J 1998; 11: 377-383.

36. Hisada T, Nasuhara Y, Chung KF. Involvement of heme oxygenase-1 in ozone-induced airway inflammation and hyperresponsiveness. Eur J Pharmacol 2000; 399: 229-234

37. Lim S, Groneburg D, Fischer A, et al. Expression of heme oxygenase izoenzyme 1 and 2 in normal and asthmatic airways - effect of inhaled corticosteroid. Am J Respir Crit Care Med 2000; 162: 1912-1918.

38. Zayasu K, Sekizawa K, Okinaga S, Yamaya M, Ohrui $\mathrm{T}$, Sasaki H. Increased carbon monoxide in exhaled air of asthmatic patients. Am J Respir Crit Care Med 1997; 156: 1140-1143.

39. Yamaya M, Sekizawa K, Ishizuka S, Monma M, Sasaki H. Exhaled carbon monoxide levels during treatment of acute asthma. Eur Respir J 1999; 13: 757760.

40. Yamaya M, Sekizawa K, Ishizuka S, Monma M, Mizuta K, Sasaki H. Increased carbon monoxide in exhaled air of subjects with upper respiratory tract infections. Am J Respir Crit Care Med 1998; 158: 311314.

41. Horváth I, Donnelly LE, Kiss A, Paredi P, Kharitonov SA, Barnes PJ. Raised levels of exhaled carbon monoxide are associated with an increased expression of heme oxygenase-1 in airway macrophages in asthma: a new marker of oxidative stress. Thorax 1998; 53: 668-672.

42. Stirling RG, Kharitonov SA, Campbell D, et al. Increase in exhaled nitric oxide levels in patients with difficult asthma and correlation with symptoms and disease severity despite treatment with oral and inhaled and corticosteroids. Thorax 1998; 53: 1030 1034.

43. Uasaf C, Jatakanon A, James A, Kharitonov SA, Wilson NM, Barnes PJ. Exhaled carbon monoxide in childhood asthma. J Pediatr 1999; 135: 569-574.

44. Horváth I, Barnes PJ. Exhaled monoxides in asymptomatic atopic subjects. Clin Exp Allergy 1999; 29: 1276-1280.

45. Paredi P, Leckie MJ, Horvath I, Allegra L, Kharitonov SA, Barnes PJ. Changes in exhaled carbon monoxide and nitric oxide levels following allergen challenge in patients with asthma. Eur Respir J 1999; 13: 48-53. 
46. Horvath I, Loukides S, Wodehouse T, Kharitonov SA, Cole PJ, Barnes PJ. Increased levels of exhaled carbon monoxide in bronchiectasis: a new marker of oxidative stress. Thorax 1998; 53: 867-870.

47. Paredi $\mathbf{P}$, Shah $\mathbf{P}$, Montuschi $\mathrm{P}$, et al. Increased carbon monoxide in exhaled air of cystic fibrosis patients. Thorax 1999; 54: 917-920.

48. Antuni JD, Kharitonov SA, Hughes D, Hodson ME, Barnes PJ. Increase in exhaled carbon monoxide during exacerbations of cystic fibrosis. Thorax 2000; 55: $138-142$.

49. Jones KL, Bryan TW, Jinkins PA, et al. Superoxide released from neutrophils causes a reduction in nitric oxide gas. Am J Physiol 1998; 275: L1120-L1126.

50. Horváth I, Loukides S, Wodehouse T, Barnes PJ. Exhaled monoxides in primary ciliary dyskinesia. $\mathrm{Am}$ J Respir Crit Care Med 1998; 157: A585.

51. Paredi P, Invernizzi G, Biernacki W, Kharitonov SA, Barnes PJ. Exhaled carbon monoxide levels are elevated in diabetes and correlate with glycemia: a new test for disease monitoring? Chest 1999; 116: 1007-1011.

52. Horváth I, Borka P, Apor P, Kollai M. Carbon monoxide in exhaled air at rest and after exercise in children with cystic fibrosis. Acta Physiol Hung 1999; 86: 235-242.

53. Mikoss M, Karloczai K, Kollai M, Horváth I. Exhaled carbon monoxide in cardiopulmonary conditions associated with hypoxia. Eur Respir J 1999; 14: 227s.

54. Bálint B, Csoma Zs, Mikoss M, Herjavecz I, Horváth I. Exhaled monoxides in patients with extrinsic and intrinsic asthma. Am J Respir Crit Care Med 2000; 161: A922.

55. Tenhunen R, Marver HS, Schmid R. The enzymatic conversion of heme to bilirubin by microsomal heme oxygenase. Proc Natl Acad Sci USA 1968; 61: 748-755.

56. Choi AMK, Alam J. Heme oxygenase-1: Function, regulation, and implication of a novel stress-inducible protein in oxidant-induced lung injury. Am J Resp Cell Mol Biol 1996; 5: 9-19.

57. Otterbein LE, Sylvester SL, Choi AMK. Hemoglobin provides protection against lethal endotoxemia in rats: the role of heme oxygenase-1. Am J Respir Cell Mol Biol 1995; 13: 595-601.

58. Lee PJ, Alam J, Wiegand GW, Choi AMK. Overexpression of heme oxygenase-1 in human pulmonary epithelial cells results in cell growth arrest and increased resistance to hyperoxia. Proc Natl Acad Sci USA 1996; 93: 10393-10398.

59. Poss KD, Tonegawa S. Reduced stress defence in heme oxygenase deficient cells. Proc Natl Acad Sci USA 1997; 94: 10925-10930.

60. Yachie A, Niida Y, Wada T, Igarashi N, Kaneda H. Oxidative stress causes enhanced endothelial cell injury in human heme oxygenase-1 deficiency. $J$ Clin Invest 1999; 103: 129-135.

61. Otterbein LE, Kolls JK, Mantell LL, Cook JL, Alam J, Choi AMK. Exogenous administration of heme oxygenase-1 by gene transfer provides protection against hyperoxia-induced lung injury. $J$ Clin Invest 1999; 103: 1047-1054.

62. Otterbein LE, Mantell LL, Choi AMK. Carbon monoxide provides protection against hyperoxic lung injury. Am J Physiol 1999; 276: L688-L694.

63. Soares MP, Lin Y, Anrather J, et al. Expression of heme oxygenase-1 can determine cardiac xenograft survival. Nat Med 1998; 14: 1073-1077.

64. Willis D, Moore AR, Frederick R, Willoughby DA. Heme oxygenase: a novel target for the modulation of the inflammatory response. Nat Med 1996; 2: 87-90.

65. Maines MD. Heme oxygenase: Function, multiplicity, regulatory mechanisms, and clinical application. FASEB J 1988; 2: 2557-2568.

66. Balla J, Jacob HS, Balla G, Nath K, Eaton JW, Vercellotti G. Endothelial-cell heme uptake from heme proteins: induction of sensitization and desensitization to oxidant damage. Proc Natl Acad Sci USA 1993; 90: 9285-9289.

67. Ho LP, Innes JA, Greening AP. Nitrite levels in breath condensate of patients with cystic fibrosis in contrast to exhaled nitric oxide. Thorax 1998; 53: 680-684.

68. Huszar E, Vass G, Horvath I, Herjavecz I. Expired adenosise in breath condensate of healthy subjects and patients with allergic rhinitis and asthma. Am J Respir Crit Care Med 2001; 163: A48.

69. Ho LP, Faccenda J, Innes JA, Greening AP. Expired hydrogen peroxide in breath condensate of cystic fibrosis patients. Eur Respir J 1999; 13: 103-106.

70. Hunt J, Byrns RE, Ignarro LJ, Gaston B. Condensed expirate nitrite as a home marker for acute asthma. Lancet 1995; 346: 1235-1236.

71. Montuschi P, Collins JV, Ciabattoni G, et al. Exhaled 8 -isoprostane as an in vivo biomarker of lung oxidative stress in patients with COPD and healthy smokers. Am J Respir Crit Care Med 2000; 162: 1175-1177. 